\title{
SPECIATION AND DRUG SUSCEPTIBILITY TESTING INCLUDING MINIMUM INHIBITORY CONCENTRATION FOR VANCOMYCIN IN CLINICAL ISOLATES OF ENTEROCOCCI
}

\author{
Maninder Kaur Jagdev1, Satish Gupte², Prerna Aggarwal ${ }^{3}$, Ashwini Manhas ${ }^{4}$ \\ ${ }^{1}$ Associate Professor, Department of Microbiology, Gian Sagar Medical College and Hospital, Banur, Punjab. \\ 2 Professor and HOD, Department of Microbiology, Gian Sagar Medical College and Hospital, Banur, Punjab. \\ 3 Professor, Department of Microbiology, Gian Sagar Medical College and Hospital, Banur, Punjab. \\ ${ }_{4}^{4}$ Associate Professor, Department of Microbiology, Gian Sagar Medical College and Hospital, Banur, Punjab
}

\section{ABSTRACT}

\section{BACKGROUND}

The present prospective study has been undertaken to study the species of Enterococcal isolates from various clinical samples in a tertiary care hospital and to determine their antimicrobial susceptibility pattern including MIC for vancomycin.

\section{MATERIALS AND METHODS}

A total of 70 enterococcal isolates obtained from various clinical samples were included in the study and processed according to standard protocol and speciation was done based on Facklam's conventional method. Antibacterial susceptibility pattern was determined by Kirby Bauer disc diffusion method with recommended drugs including high level gentamicin resistance. Minimum inhibitory concentration for vancomycin was done by agar dilution method.

\section{RESULTS}

Among the 70 Enterococcus isolates, 40 (58.3\%) were E. faecalis, 27 (36.6\%) E. faecium, and 3 (5\%) belonged to other Enterococcus species. ( 2 isolates of E. durans and one was E. avium). As compared to E. faecalis, resistance amongst E. faecium isolates was higher than to most of the antibiotics tested and it was found to be statistically significant for ampicillin, nitrofurantoin and vancomycin. However, tetracycline resistance was found to be higher in E. faecalis isolates as compared to E. faecium (P 0.001). High-level aminoglycoside resistance was detected in $86.6 \%$ of the total isolates. Out of 70 isolates, 6 isolates were resistant to vancomycin by both disc diffusion and agar dilution method except 1 isolate which turned out to be intermediately resistant on MIC detection. However, none of the isolate was found resistant to linezolid.

\section{CONCLUSION}

Occurrence of VRE along with HLAR calls for regular detection of vancomycin resistance promptly and accurately so as to preve nt the establishment and spread of multidrug resistant Enterococcus species.

\section{KEYWORDS}

Enterococcus, High Level Gentamicin Resistance, Minimum Inhibitory Concentration, Vancomycin Resistant Enterococcus.

HOW TO CITE THIS ARTICLE: Jagdev MK, Gupte S, Aggarwal P, et al. Speciation and drug susceptibility testing including minimum inhibitory concentration for vancomycin in clinical isolates of Enterococci. J. Evolution Med. Dent. Sci. 2016;5(99):7276-7279, DOI: 10.14260/jemds/2016/1646

\section{BACKGROUND}

The Enterococci have emerged over the last decade as one of the most important nosocomial pathogens, being isolated from a variety of clinical conditions like urinary tract infections and bacteraemias. ${ }^{1}$ The emergence of vancomycin resistant Enterococci (VRE) in addition to the increasing incidence of high level aminoglycoside resistance (HLAR), presents a serious challenge for clinicians treating the patients with infections due to Enterococci. ${ }^{2}$ The species most commonly implicated in human infections is Enterococcus faecalis, but in the recent times, increasing occurrence of Enterococcus

Financial or Other, Competing Interest: None.

Submission 07-11-2016, Peer Review 01-12-2016,

Acceptance 07-12-2016, Published 12-12-2016.

Corresponding Author:

Dr. Maninder Kaur Jagdev,

Associate Professor,

Department of Microbiology,

Gian Sagar Medical College,

Ramnagar, Rajpura,

Patiala, Punjab.

E-mail:drmaninderk@yahoo.co.in

DOI: $10.14260 /$ jemds/2016/1646 faecium is of particular concern due to high resistance to antibiotics especially in nosocomial settings. ${ }^{3}$

The present prospective study has been undertaken to speciate Enterococcal isolates from various clinical samples in a tertiary care hospital, to determine their antimicrobial susceptibility pattern and to carry out MIC detection for vancomycin using agar dilution method, enabling important therapeutic decisions to be made depending on these findings.

\section{MATERIALS AND METHODS}

The present study was carried out at a tertiary care hospital in Punjab. A total of 70 Enterococcal isolates were obtained from various clinical samples, during the study period from June 2015 to November 2015.

The isolates were identified to the genus level by culture characteristics, Gram's stain, catalase negativity, growth on and blackening of bile-esculin agar, heat tolerance $\left(60^{\circ} \mathrm{C}\right.$ for 30 minutes) and salt tolerance $(6.5 \% \mathrm{NaCl}) .{ }^{4}$ Speciation was based on Facklam's conventional method: fermentation of arabinose, mannitol, raffinose and sorbitol. The carbohydrate fermentation reactions were performed in brain heart infusion broth containing $1 \%$ carbohydrate with bromocresol purple as an indicator. Pyruvate acidification was performed in $1 \%$ 
pyruvate broth with bromothymol blue as an indicator. Other biochemical reactions included deamination of arginine, pigment production, motility determination and tellurite reduction. 4,5

Antimicrobial susceptibility testing was performed by the standard disc diffusion method as recommended by the National Committee for Clinical Laboratory Standards (NCCLS, 2010). ${ }^{6}$ The following antibiotics were tested: ampicillin $(10$ $\mu \mathrm{g})$, ciprofloxacin $(5 \mu \mathrm{g})$, erythromycin $(15 \mu \mathrm{g})$, tetracycline $(30 \mu \mathrm{g})$, vancomycin $(30 \mu \mathrm{g})$, teicoplanin $(30 \mu \mathrm{g})$ and linezolid (30 $\mu \mathrm{g})$. For urine isolates, susceptibility testing for nitrofurantoin $(300 \mu \mathrm{g})$ was also done. E. faecalis ATCC 29212 (HiMedia Laboratories Pvt. Ltd., Mumbai, India) was used as a quality control strain. Detection of high-level aminoglycoside resistance (HLAR) was performed by disc diffusion method using disc containing $120 \mu \mathrm{g}$ of gentamicin. A diameter of the zone of inhibition $<6 \mathrm{~mm}$ indicated resistance, 7-9 $\mathrm{mm}$ indicated that the test was inconclusive and $\geq 10 \mathrm{~mm}$ indicated susceptibility. ${ }^{6}$

MIC of vancomycin was determined for enterococcal isolates by agar dilution method. E. faecalis strain ATCC 29212 and E. faecalis ATCC 51299 were used as sensitive and resistant control strains respectively. Mueller Hinton agar was supplemented with different concentrations of vancomycin (HiMedia) ranging from $0.25 \mu \mathrm{g} / \mathrm{mL}$ to $128 \mu \mathrm{g} / \mathrm{mL}$. Ten microlitres of bacterial culture was spot inoculated after adjusting the turbidity with 0.5 McFarland standard. The plates were incubated at $37^{\circ} \mathrm{C}$ for 24 hours and examined for growth. Any amount of growth was considered as significant. The minimum concentration of vancomycin which inhibited bacterial growth was considered as MIC. Organisms with "intermediate" levels of resistance were included in the percentage of resistant organisms for final analysis.

\section{RESULTS}

A total of 70 Enterococcus isolates were obtained from various clinical samples during the study period. These included 40 $(58.3 \%)$ isolates of E. faecalis, 27 (36.6\%) isolates of E. faecium and three $(5.0 \%)$ isolates belonging to other species, which included two isolates of E. durans and one isolate of E. avium. E. faecalis was the predominant species in urine and pus samples. All the five isolates obtained from blood culture were E. faecium [Table 1].

As compared to E. faecalis, resistance amongst E. faecium isolates was higher to most of the antibiotics tested and it was found to be statistically significant for ampicillin ( $P$ 0.008), nitrofurantoin (P 0.042) and vancomycin (P 0.035). However, tetracycline resistance was found to be significantly higher in E. faecalis isolates as compared to E. faecium (P 0.001). HLGR was detected in $86.6 \%$ of the total isolates [Table 2]. None of the Enterococcal isolate was resistant to linezolid. Vancomycin resistance was observed in $6(8.5 \%)$ isolates by disc diffusion method, out of which four isolates were resistant to teicoplanin as well. All the VRE isolates were also resistant to ciprofloxacin, ampicillin and gentamicin.

Out of six VRE isolates, four isolates had MIC of $>128$ $\mu \mathrm{g} / \mathrm{mL}$, one isolate had MIC of $64 \mu \mathrm{g} / \mathrm{mL}$ and remaining one isolate turned out to be intermediately resistant to vancomycin having MIC of $16 \mu \mathrm{g} / \mathrm{mL}$. Majority of the vancomycin sensitive Enterococcal isolates (39 isolates) showed MIC of $4 \mu \mathrm{g} / \mathrm{mL}$ [Table 3].
Of the six VRE isolates, five were identified as E. faecium and one was E. faecalis. Five VRE isolates were obtained from urine samples and one was from pus sample. Of all the VRE isolates, four were recovered from inpatients and one isolate was from outdoor patient.

\begin{tabular}{|c|c|c|c|c|}
\hline \multirow[b]{2}{*}{ Source } & \multirow{2}{*}{$\begin{array}{c}\text { E. } \\
\text { faecalis } \\
(40)\end{array}$} & \multirow{2}{*}{$\begin{array}{c}E . \\
\text { faecium } \\
(27)\end{array}$} & \multicolumn{2}{|c|}{ Other Species (3) } \\
\hline & & & \begin{tabular}{|c|} 
E. \\
durans
\end{tabular} & $\begin{array}{c}\text { E. } \\
\text { avium }\end{array}$ \\
\hline Urine (45) & 29 & 15 & 1 & \\
\hline Blood (5) & & 5 & & \\
\hline $\begin{array}{l}\text { Pus and Soft } \\
\text { Tissues (14) }\end{array}$ & 9 & 4 & 1 & \\
\hline $\begin{array}{l}\text { Vitreous } \\
\text { Fluid (1) }\end{array}$ & & 1 & & \\
\hline $\begin{array}{c}\text { Peritoneal } \\
\text { Fluid (1) }\end{array}$ & & 1 & & \\
\hline Bile (1) & 1 & & & \\
\hline $\begin{array}{c}\text { ET } \\
\text { Secretions (1) }\end{array}$ & & 1 & & \\
\hline $\begin{array}{l}\text { High Vaginal } \\
\text { Swab (1) }\end{array}$ & & & & 1 \\
\hline $\begin{array}{c}\text { Product of } \\
\text { Conception (1) }\end{array}$ & 1 & & & \\
\hline
\end{tabular}

Table 1. Source and Speciation of Enterococcal isolates

\begin{tabular}{|c|c|c|c|}
\hline Antibiotic & $\begin{array}{c}\text { E. } \\
\text { Faecalis }\end{array}$ & $\begin{array}{c}\text { E. } \\
\text { Faecium }\end{array}$ & $\begin{array}{c}\text { Other } \\
\text { Species }\end{array}$ \\
\hline Ampicillin & 40 & 81.4 & 33.3 \\
\hline Ciprofloxacin & 95 & 100 & 100 \\
\hline Erythromycin & 100 & 100 & 100 \\
\hline Nitrofurantoin* & 34.4 & 66.6 & 0 \\
\hline $\begin{array}{l}\text { Gentamicin } \\
\text { (HLAR) }\end{array}$ & 82.5 & 92.5 & 66.6 \\
\hline Tetracycline & 82.5 & 44.4 & 33.3 \\
\hline Teicoplanin & 2.5 & 11.1 & 0 \\
\hline Vancomycin & 2.5 & 18.5 & 0 \\
\hline Linezolid & 0 & 0 & 0 \\
\hline \multicolumn{4}{|c|}{$\begin{array}{c}\text { Table 2. Antibiotic Resistance (\%) in Enterococci by } \\
\text { Kirby-Bauer disc Diffusion Method }\end{array}$} \\
\hline
\end{tabular}

\begin{tabular}{|c|c|c|c|c|c|c|c|c|}
\hline Species & $\begin{array}{c}1 \\
\mu \mathrm{g} / \mathrm{mL}\end{array}$ & $\begin{array}{c}2 \\
\mu \mathrm{g} / \mathrm{ml}\end{array}$ & $\begin{array}{c}4 \\
\mu \mathrm{g} / \mathrm{mL} \\
\end{array}$ & \begin{tabular}{|c|}
8 \\
$\mu \mathrm{g} / \mathrm{mL}$
\end{tabular} & \begin{tabular}{|c|}
16 \\
$\mu \mathrm{g} / \mathrm{mL}$
\end{tabular} & \begin{tabular}{|c|}
32 \\
$\mu \mathrm{g} / \mathrm{mL}$ \\
\end{tabular} & \begin{tabular}{|c|}
64 \\
$\mu \mathrm{g} / \mathrm{mL}$ \\
\end{tabular} & $\begin{array}{c}128 \\
\mu \mathrm{g} / \mathrm{mL}\end{array}$ \\
\hline \begin{tabular}{|c|} 
E. Faecalis \\
$(40)$
\end{tabular} & 2 & 10 & 27 & - & 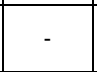 & & - & 1 \\
\hline \begin{tabular}{|c|} 
E. Faecium \\
$(27)$
\end{tabular} & - & 10 & 12 & - & 1 & & 1 & 3 \\
\hline \begin{tabular}{|l|} 
Others (3) \\
\end{tabular} & 1 & 2 & - & - & - & - & - & - \\
\hline
\end{tabular}

\section{DISCUSSION}

In our study, E. faecalis was the predominant species followed by E. faecium and this is in concordance with other studies from different parts of the country. ${ }^{2,7,8}$ However, various other studies have shown E. faecium to be responsible for a larger number of Enterococcal infections as compared to E. faecalis.9,3 Apart from the predominant isolates of E. faecalis and $E$. faecium, two isolates of E. durans and one isolate of $E$. avium were also obtained in this study. Mohanty et al has also reported E. durans and E. avium, as the non-E. faecalis non-E. 
faecium isolates in their study. ${ }^{10}$ In this study, a large number of isolates (46.29\%) were from urine which goes parallel with the findings from other studies. ${ }^{2,11}$ Various studies have reported a greater proportion of E. faecium in blood cultures and E. faecalis in cultures of samples from other sites. ${ }^{12,13}$ In this study as well, we had similar findings. All the five isolates from blood cultures were E. faecium whereas E. faecalis constituted $69.4 \%$ and $61.5 \%$ of the total isolates found in urine and pus respectively.

The intestinal location of Enterococci and their abundance of plasmids and transposons suggests that they serve as a significant reservoir and transmitter of genetic information, including drug resistance genes, to other Gram-positive organisms in the gut, much in the way Escherichia coli is sometimes viewed as a reservoir of information for Gramnegative bacteria. ${ }^{14}$ Enterococci has been recognised as an important global cause of nosocomial infections, with emphasis on related problem of multidrug resistance. In this study, resistance amongst E. faecium isolates was found to be higher to most of the antibiotics tested except tetracycline, as compared to E. faecalis. This has been reported in earlier studies as well.7,15 In our study, the highest resistance was seen against erythromycin, which is in agreement with other studies carried out in India. 16,17

In this study, occurrence of HLGR was $86.6 \%$ amongst the total Enterococcal isolates, being higher in E. faecium isolates as compared to E. faecalis although the difference was not statistically significant (P 0.294). Mendiratta et al have also reported greater resistance to high level gentamicin among E. faecium as compared to E. faecalis isolates. ${ }^{7}$ Study conducted by Karmarkar et al in Mumbai have reported HLGR prevalence to be as high as 100 percent for both the species. ${ }^{3}$

There is now rampant use of vancomycin in hospitals, since it is used for treating infections with HLAR strains of Enterococci as well as methicillin-resistant $\mathrm{S}$. aureus. Excessive use of vancomycin has been found to be a risk factor for infection or colonisation by VRE. 18 In this study, vancomycin resistance was observed in $6(8.5 \%)$ Enterococcal isolates. Praharaj et al have also reported $8.7 \%$ of all Enterococcal isolates as vancomycin resistant. ${ }^{1}$ Another study carried out in Chandigarh had identified 5.5 percent Enterococcus isolates from urine specimens as VRE. ${ }^{19}$ However, two other studies from North India have reported vancomycin resistance in only 1\% and 2\% of all Enterococcal isolates respectively. ${ }^{16,20}$ Out of six VRE isolates, four isolates were also resistant to teicoplanin indicating Van A phenotype and remaining two isolates belonged to Van B phenotype. The results of our study were based on phenotypic methods alone. Genotypic methods could not be performed in conjunction with phenotypic methods to get more accurate information.

\section{CONCLUSION}

Integrated approach to limit the spread of VRE includes routine testing of all Enterococcal isolates for vancomycin resistance at least by vancomycin agar screen test, judicious use of vancomycin, rapid isolation of patients suspected to have VRE infections and effective surveillance mechanisms.

\section{REFERENCES}

1. Praharaj I, Sujatha S, Parija SC. Phenotypic \& genotypic characterization of vancomycin resistant enterococcus isolates from clinical specimens. Indian J Med Res 2013;138(4):549-56.

2. Shrihari N, Kumidini TS, Karadesai SG, et al. Speciation of enterococcal isolates and antibiotic susceptibility test including high level aminoglycoside resistance and minimum inhibitory concentration for vancomycin. Int J Biol Med Res 2011;2(4):865-9.

3. Karmarkar MG, Gershom ES, Mehta PR. Enterococcal infections with special reference to phenotypic characterization \& drug resistance. Indian J Med Res 2004;119 Suppl:22-5.

4. Facklam RR, Collins MD. Identification of enterococcus species isolated from human infections by a conventional test scheme. J Clin Microbiol 1989;27(4):731-4.

5. Facklam RR, Teixeira LM. Enterococcus. In: Lollier L, Balows A, Sussman M, eds. Topley \& Wilson's microbiology and microbial infections. 9th ed. New York: Oxford University Press 1998:669-82.

6. Clinical and Laboratory Standards Institute. Performance standards for antimicrobial susceptibility testing; Twenty fourth informational supplement. Wayne, Pa, USA: CLSI 2014;34 (1):M100-S24.

7. Mendiratta DK, Kaur H, Deotale V, et al. Status of high level aminoglycoside resistant in enterococcus faecium and enterococcus faecalis in rural hospital of central India. Indian J Med Microbiol 2008;26(4):369-71.

8. Jesudason MV, Pratima VL, Pandian R, et al. Characterization of penicillin resistant enterococci. Indian J Med Microbiol 1998;16(1):16-8.

9. Kapoor L, Randhawa VS, Deb M. Antimicrobial resistance of enterococcal blood isolates at a pediatric care hospital in India. Jpn J Infect Dis 2005;58(2):101-3.

10. Mohanty S, Jose S, Singhal R, et al. Species prevalence and antimicrobial susceptibility of enterococcal isolates in a tertiary care hospital of north India. Southeast Asian J Trop Med Public Health 2005;36(4):962-5.

11. Agarwal J, Kalyan R, Singh M. High-level aminoglycoside resistance and $\beta$-lactamase production in enterococci at a tertiary care hospital in India. Jpn J Infect Dis 2009;62(2):158-9.

12. Gray JW, Stewart D, Pedler SJ. Species identification and antibiotic susceptibility testing of enterococci isolated from hospitalized patients. Antimicrob Agents Chemother 1991;35(9):1943-5.

13. Simonsen GS, Småbrekke L, Monnet DL, et al. Prevalence of resistance to ampicillin, gentamicin and vancomycin in Enterococcus faecalis and Enterococcus faecium isolates from clinical specimens and use of antimicrobials in five Nordic hospitals. J Antimicrob Chemether 2003;51(2):323-31.

14. MacIntyre CR, Empson M, Boardman C, et al. Risk factors for colonization with vancomycin-resistant enterococci in a Melbourne hospital. Infect Control Hosp Epidemiol 2001;22(10):624-9.

15. Bhat KG, Paul C, Ananthakrishna NC. Drug resistant enterococci in a south Indian hospital. Trop Doct 1998;28(2):106-7. 
16. Mathur P, Kapil A, Chandra R, et al. Antimicrobial resistance in enterococcus faecalis at a tertiary care centre of northern India. Indian J Med Res 2003;118:258.

17. Fernandes SC, Dhanashree B. Drug resistance \& virulence determinants in clinical isolates of enterococcus species. Indian J Med Res 2013;137(5):981-5.

18. Clewell DB. Movable genetic elements and antibiotic resistance in enterococci. Euro J Clin Microbiol Infect Dis 1990;9(2):90-102.
19. Taneja N, Rani P, Emmanuel R, et al. Significance of vancomycin resistant enterococci from urinary specimens at a tertiary care centre in northern India. Indian J Med Res 2004;119:72-4.

20. Kaur N, Chaudhary U, Aggarwal R, et al. Emergence of VRE and their antimicrobial sensitivity pattern in a tertiary care teaching hospital. J Med Biol Sci 2009;8(1):26-32. 